\title{
Adoção Suficientemente Boa: Experiência de um Casal com Filhos Biológicos ${ }^{1}$
}

\author{
Livia Kusumi Otuka \\ Universidade de São Paulo - Ribeirão Preto \\ Fabio Scorsolini-Comin \\ Universidade Federal do Triângulo Mineiro \\ Manoel Antônio dos Santos ${ }^{2}$ \\ Universidade de São Paulo - Ribeirão Preto
}

\begin{abstract}
RESUMO - A partir de um estudo de caso, aborda-se a experiência de adoção de uma criança de quatro meses de idade por um casal com três filhos biológicos. Os dados obtidos por entrevistas semiestruturadas mostraram que a parentalidade adotiva foi experienciada em meio a temores/fantasias de perda/roubo da criança adotada. Isso pode ser associado ao modo como foi realizada a adoção, sem os cuidados preconizados pelo Estatuto da Criança e do Adolescente e a nova lei de adoção. O processo de adoção figurou para os adotantes como fonte de intensa carga emocional, permeada por sentimentos ambivalentes que merecem atenção dos profissionais da Psicologia. Os resultados ilustram a necessidade de atenção psicossocial-jurídica a adotantes, adotado e família biológica do adotado.
\end{abstract}

Palavras-chave: adoção; pais adotivos; relações familiares; motivação para adoção.

\section{Good Enough Adoption: The Experience of a Couple with Biological Children}

\begin{abstract}
This case study investigates the experience of adoption of a four months old child by a couple who already possessed three biological children. The analysis of data, obtained by means of a semi-structured interview, showed that the adoptive parenthood experienced thorough fears of loss of the adopted child. These feelings seemed to be related to the way in which the adoption came to terms, without following all necessary steps set up by the new Brazilian adoption law. For the adopting couple, the adoption process was an intense emotional experience, which was permeated by feelings of ambivalence that deserve the attention of psychology professionals. Results show the need of offering psychosocial and legal attention both to the adopters, the adopted and the family.
\end{abstract}

Keywords: adoption; foster parents; family relations, motivation for adoption.

Estudos dedicados à adoção no contexto de investigação clínica (Gomes \& Iyama, 2001; Iyama \& Gomes 2005; Levinzon, 2006; Otuka, 2009; Rosa, 2008; Santos, Raspantini, Silva \& Escrivão, 2003; Scorsolini-Comin \& Santos, 2008) apontam a prevalência de uma constelação de elementos específicos na vivência das famílias adotivas: preconceitos, fantasias e medos permeiam o universo da adoção, tais como fantasias inconscientes de apropriação ("roubo") da criança de outrem. Uma das possibilidades mais instigantes que se abrem é a de que as investigações avaliem tais elementos a partir dos diferentes modos como a adoção pode se dar: pelas vias legais, pelas vias informais (adoção pronta), entre parentes, entre desconhecidos, com ou sem a participação de intermediários, entre outras possibilidades discutidas na nova lei da adoção (Brasil, 2009; Ghesti-Galvão, 2008).

Segundo Winnicott $(1953 / 1997)$ a adoção pode ser compreendida em duas amplas categorias. Na primeira, encontram-se os problemas relacionados de modo simples à situação da adoção, que não geram necessariamente ansiedade, visto que, se a adoção transcorre bem, caracteriza uma história comum, com contratempos e perturbações que

1 Apoio: FAPESP

2 Endereço para correspondência: FFCLRP-USP, Departamento de Psicologia, Av. Bandeirantes, 3900, Monte Alegre, 14040-901, Ribeirão Preto, SP. E-mail: masantos@ffclrp.usp.br fazem parte de qualquer itinerário humano. A segunda categoria, entretanto, refere-se às complicações resultantes do manejo inadequado do bebê antes da adoção, o que envolve não apenas questões clínicas como também sociais e legais, incluindo a segurança jurídica na passagem da criança de uma família a outra (Ghesti-Galvão, 2008). Nesse ponto, a mãe adotiva estaria lidando com uma criança que sofreu privações ou deprivações e também com a família de origem da criança, muitas vezes privada de condições mínimas de sobrevivência e acesso aos direitos de cidadania. A família de origem estaria privada tanto de informações e procedimentos para efetivar a validade de seu consentimento para a adoção, como também de um olhar suficientemente generoso por parte dos psicólogos e de outros profissionais que acompanhariam esse processo. A deprivação, segundo Gomes (2006), é definida como a perda de algo bom, que havia sido positivo na experiência do bebê até determinado momento, tendo sido retirado por um período de tempo maior do que aquele durante o qual a criança é capaz de recordar-se da experiência. Nessas condições desfavoráveis, a mãe adotiva poderia tornar-se, além de mãe, "terapeuta de uma criança carente" (Winnicott, 1954/1997), exagerando em seus cuidados para constituir-se como uma mãe suficientemente boa.

Winnicott (1955/1997) destaca a importância da estabilidade e da continuidade do novo lar para o desenvolvimento saudável da criança. A adoção, assim, caracterizar-se-ia como 
uma vivência positiva, sendo frequentemente associada a uma prática que tende a ser bem-sucedida, na medida em que a nova família possa se firmar enquanto suficientemente boa para a criança ou o adolescente adotado. O desafio, portanto, passa pela necessidade de que a nova família seja capaz de oferecer um ambiente seguro e estável no qual a criança possa crescer, identificar-se, tomar contato com a sua história e, enfim, criar a sua própria experiência.

A literatura acerca da adoção comumente não diferencia famílias constituídas apenas pela parentalidade adotiva de arranjos familiares "mistos", isto é, configurados por vínculos de parentesco consanguíneo e adotivo (Costa, 2005; Palacios, Sánchez-Sandoval \& León, 2004; Solon, 2009). Embora menos frequentes no universo da adoção, esses arranjos não são tão incomuns e requerem a atenção dos investigadores do campo da Psicologia. Segundo estudo realizado por Costa e Campos (2003), pouco mais da metade das famílias adotantes do Distrito Federal, nos anos 1998 e 1999, tinham filhos biológicos em comum, um achado que se opõe à ideia corrente de que a impossibilidade de gerar filhos biológicos seja uma das principais razões para a adoção. Somando-se essa informação ao tempo mais frequente de convivência do casal (de 11 a 15 anos e acima de 20 anos), pode-se inferir que a fase do ciclo de vida da família pode influenciar na decisão de adotar uma criança. Assim, famílias cujos filhos estejam vivenciando a adolescência ou o início da vida adulta poderiam apresentar maior disponibilidade para a adoção.

Nesse sentido, como se daria a adoção na situação de um casal que tinha filhos biológicos antes de iniciar esse processo? Como seria vivenciada a parentalidade adotiva em comparação com a biológica, experienciada anteriormente? Como essas distintas formas de ser pai e de ser mãe coexistem e se influenciam mutuamente? Quais as fantasias conscientes/inconscientes que permeariam esse processo singular de adoção?

Considerando essas questões, o objetivo do presente estudo foi investigar a experiência da adoção por um casal que já tinha filhos biológicos, destacando suas fantasias conscientes e inconscientes em relação ao processo de adoção, bem como os modos de construção da parentalidade adotiva em comparação à biológica.

\section{Método}

Trata-se de um estudo do tipo descritivo e exploratório, conduzido sob o enfoque qualitativo de pesquisa. A estratégia metodológica adotada é o estudo de caso (Peres \& Santos, 2005), entendendo-se que essa opção é adequada aos objetivos do estudo. Nesse tipo de estratégia metodológica existe, por um lado, uma limitação na extensão da casuística investigada, mas, por outro lado, o estudo de caso permite uma abordagem em profundidade do fenômeno focalizado.

A opção pelo estudo de caso também se ajusta ao marco teórico adotado para a interpretação dos dados: a psicanálise, particularmente no referencial winnicottiano. Nessa concepção teórica é valorizada a singularidade das experiências emocionais e o foco é colocado na compreensão da intersubjetividade, entendendo-se que o ser humano se constitui a partir de suas relações com o outro e o ambiente. Portanto, é preciso analisar essas experiências na particularidade da constituição de cada sujeito. No presente estudo, esse olhar privilegia o vértice do discurso parental como fonte primária de informações.

\section{Participantes}

O estudo contou com a participação de um casal que efetivou a adoção de uma criança. Como critério para a inclusão dos participantes foi definido que o casal deveria ter pelo menos um filho biológico, nascido antes do processo de adoção, e consentir em colaborar voluntariamente com o estudo. Arlete (41 anos) e Carlos (49) estavam casados havia 20 anos $^{3}$. Tiveram três filhos biológicos: Emanoel (20), Juliano (18) e George (16). Posteriormente, adotaram Gabriel, aos quatro meses, o qual, no momento da entrevista, encontrava-se com seis anos. Arlete completou o Ensino Médio e trabalhava como auxiliar de Enfermagem; Carlos, por sua vez, concluiu o Ensino Fundamental e trabalhava no ramo de aparelhos eletrônicos. Pais e filhos habitavam uma residência própria.

\section{Instrumento}

Para a coleta de dados, foram utilizados: (a) questionário de caracterização sociodemográfica, contendo questões relativas à idade de cada membro da família, nível de escolaridade, profissão/ocupação, estado civil, religião e renda familiar; e (b) roteiro de entrevista semiestruturada, delineado especialmente para atender aos objetivos do presente estudo, com base em investigações similares desenvolvidas anteriormente (Otuka, 2009; Pereira \& Santos, 1998).

Esse roteiro era composto por questões abertas que exploravam a experiência do casal adotante em relação ao processo de adoção, particularmente os motivos que levaram à busca desse recurso, suas expectativas anteriores em relação ao nascimento dos filhos biológicos e à chegada da criança adotiva, suas vivências do exercício da parentalidade e suas concepções acerca da criança adotada.

\section{Procedimento}

Para viabilizar o acesso aos participantes foi contatada a coordenação de um serviço-escola de Psicologia, que dispõe de atendimento especializado em adoção (Grupo de Assistência Integral à Adoção - GAIA). A pesquisadora obteve a autorização do serviço para realizar a pesquisa com seus usuários, além do consentimento do casal, que foi previamente consultado pela coordenação do serviço. A entrevista foi realizada com ambos os cônjuges em uma sala do próprio serviço, no decorrer de um único encontro, com duração de 90 minutos. A entrevista foi audiogravada e, posteriormente, transcrita na íntegra.

3 Para preservar o anonimato dos participantes, os nomes próprios referidos neste estudo foram substituídos por pseudônimos. 
O método empregado para o tratamento dos dados foi a análise de conteúdo temática (Triviños, 1987) e a interpretação dos dados apoiou-se no referencial psicanalítico. $\mathrm{Na}$ tentativa de compreender a vivência do casal, após a realização de várias releituras do material transcrito, foram identificadas unidades de significado e elaboradas categorias de análise. Para a melhor apreensão da história familiar do casal entrevistado, optou-se por apresentar uma análise vertical do material. Este estudo foi aprovado pelo Comitê de Ética em Pesquisa da Faculdade de Filosofia, Ciências e Letras de Ribeirão Preto da Universidade de São Paulo.

\section{Resultados e Discussão}

Carlos tinha 26 anos e Arlete contava com 18 anos quando começaram a namorar. Conheceram-se por serem vizinhos e terem vários amigos em comum. Após dois anos de namoro e relacionamento afetivo-sexual, o casal relata que vivenciou uma gravidez não-programada, antes do casamento. Arlete explica, entretanto, que não houve oposição por parte de seus pais, que receberam bem a notícia, uma vez que Carlos era mais velho e maduro, e todos acreditaram que eles teriam um bom relacionamento juntos.

O casal, da mesma forma que lidou com a notícia, parece ter encarado o desenrolar da gravidez com naturalidade, sem temores ou maiores dificuldades nesse período. Arlete relata não se lembrar de quais eram suas expectativas em relação ao casamento, por não ter pensado sobre o assunto. Carlos, por sua vez, refere-se ao desejo de ter filhos. A associação entre a maternidade/paternidade e a união conjugal parece fazer sentido, uma vez que, segundo Sarti (1996), é por meio dos descendentes que a família estaria, enfim, construída e consolidada como unidade.

Em relação à parentalidade biológica, Carlos relata a alegria vivenciada no dia do nascimento do primeiro filho, o momento em que se sentiu pai pela primeira vez. Pode-se notar, nesse sentido, a satisfação com os aspectos biológicos da parentalidade. Deve-se levar em conta, ainda, o contexto que envolvia a situação do novo casal. Vivenciando uma nova experiência com o casamento, a gravidez e o apoio de seus pais, Arlete e Carlos descrevem o momento do nascimento do filho como fonte de intenso contentamento. "Ah, quando o Emanoel nasceu, né... Que eu vi ele lá no, como que chama aquele lugar? [...] No berçário... Gente [risos]... Foi muito gostoso." (Carlos)

A alegria de Carlos pode estar relacionada à comprovação de sua potência masculina expressa como fertilidade, a qual se concretizou por meio da gravidez de sua esposa e do nascimento de seu primeiro filho (Schettini, Amazonas \& Dias, 2006). Acrescente-se a isso o significado específico de tornar-se pai de um filho do sexo masculino. Arlete explica que as complicações de saúde do filho biológico, Juliano, no momento do parto, foram as maiores dificuldades enfrentadas com a vinda dos filhos biológicos. "Foi com o segundo filho [abaixa o tom de voz]... Que nasceu... Ele passou da hora de nascer... Teve anóxia, né... Aquele lá foi bravo, né [dirige o olhar para Carlos]. Aquele lá nós sofremos... Mas superamos, passou." (Arlete)
A participante revela que o filho sofreu uma paralisia cervicobraquial, tendo que iniciar um tratamento fisioterápico quando contava com apenas 14 dias de vida, o que se constituiu em um evento traumático, um obstáculo que, felizmente, foi superado pela família. Segundo Winnicott (1962/1990), para que a mãe-ambiente possa refletir seu filho, identificando suas necessidades, é necessário que, intuitivamente, ela o compreenda. A "preocupação materna primária", nesse sentido, poderia ser definida como a intensa identificação da mãe com o seu filho, um estado necessário ao desenvolvimento emocional da criança (Iyama \& Gomes, 2005). Ao relatar os cuidados dispensados a Juliano, pode-se notar que Arlete parecia vivenciar o estado emocional descrito por Winnicott, no precoce estágio de desenvolvimento em que seu filho se encontrava. A mãe parecia compreender suas necessidades, suprindo-as e lidando com as dificuldades de seu bebê como uma mãe suficientemente boa.

Assim, a partir do relato do casal, é possível apreender que o segundo filho constituiu-se como aquele cujas dificuldades mostram-se mais evidentes para os familiares, com diversas queixas comportamentais e escolares. Nessa vertente, torna-se importante refletir sobre quais seriam as concepções de Arlete e Carlos acerca do filho e do papel que o mesmo ocupa em sua dinâmica familiar. Destacando a concepção de Winnicott (1965/1997) sobre o sintoma como um sinal de esperança, pode-se refletir que a dificuldade apresentada pelo filho possa estar relacionada a falhas em seu desenvolvimento precoce, as quais mereceriam a atenção devotada dos pais, para que pudessem ser reparadas a partir do provimento de um ambiente suficientemente bom.

A respeito do filho adotivo, Gabriel, é importante ressaltar que os participantes não tinham a intenção de adotá-lo. A decisão ocorreu sem qualquer planejamento prévio. Arlete apresenta como principal motivação para a adoção o altruísmo, seu desejo de ajudar o próximo. Esse "próximo" é descrito, em seu relato, como uma dupla (mãe biológica e seu bebê) em situação de penúria material e afetiva. Explica que, por trabalhar como técnica de Enfermagem na área de ginecologia e obstetrícia, teve contato com Joana, mãe de Gabriel. Conta que esta, por não ter condições de criar o filho, pedia-lhe ajuda constantemente para comprar alimentos, roupas e até mesmo para cuidar de Gabriel, quando este se encontrava doente.

E foi indo, foi até uns quatro meses isso, essa vida... Menininho voltava, ia e voltava... Ai falei: "ó, vamos fazer o seguinte... Deixa a criança aqui, deixa a criança aqui que eu cuido... A hora em que você arrumar um serviço..." Porque ela vivia falando que ia arrumar, trabalhar, né, que ia fazer isso e aquilo... "A hora em que você tiver com tudo acertado, ai você pode levar o menino... Mas deixa que eu cuido por enquanto..." Porque eu tava sustentando a criança e a família, cada vez que ela vinha, levava cesta básica, levava um monte de coisas. (Arlete)

Assim, com o passar do tempo e o desaparecimento de Joana, Arlete acabou entrando com o pedido de adoção de Gabriel e obteve, após dois anos, sua guarda definitiva. Vale ressaltar que, de acordo com Levinzon (2004), o desejo de ajudar uma criança, por si só, não se constitui como bom prognóstico para a adoção, uma vez que o desejo dos pais de 
exercer a parentalidade deve estar claro para os mesmos. É preciso que o filho adotivo ocupe um espaço no imaginário e nas fantasias dos pais e da família. Seria interessante pensar, assim, se haveria outras motivações que levaram Carlos e Arlete a adotarem Gabriel, e que possíveis consequências tal adoção poderia ter para o amadurecimento da criança. Haveria, nesse caso, um espaço para Gabriel no imaginário do casal em questão? Estaria presente o desejo de exercer a parentalidade, além do "querer ajudar" pessoas desamparadas, conforme relatado pelo casal?

Igual outro dia [falaram]: "Ê, Gabriel, a sua mãe faz tudo, tem que agradecer". Você entendeu, tipo uma cobrança? Ele tem que ser certo porque eu adotei ele? Você entendeu? Eu não gosto desse tipo de coisa. (Arlete)

Arlete rejeita a visão sobre si própria como uma mãe-benfeitora, a qual o filho deve respeito e gratidão. Em sua fala, afirma amar Gabriel, sentimento que a levou a tomar a decisão de adotá-lo, esperando que o mesmo retribua o seu amor, não como uma cobrança por tê-lo ajudado, mas pelo fato de amá-la simplesmente. No discurso da participante fica claro o "querer ter mais um filho", o que demonstra que o simples desejo de ajudar não se constituiu como o único fator motivador para a adoção. Uma interpretação possível é a de que houve uma construção do lugar desse novo filho a partir de uma situação de cuidados que foram generosamente oferecidos à díade mãe biológica-bebê. Embora, inicialmente, esse anseio de auxiliar o próximo tenha sido alimentado unicamente pelo vínculo de humanidade e solidariedade. Por outro lado, a mãe expressa nitidamente sua expectativa de que haja, de algum modo, retribuição de seu investimento amoroso na criança. Portanto, uma contrapartida que a compensasse por seus esforços e pela devoção empenhada. Essa expectativa de reciprocidade, se não for bem esclarecida e elaborada, pode levar a criança a se esforçar para ser o que os pais querem que ela seja, em detrimento de seu verdadeiro self (Winnicott, 1957/1982).

Segundo Schettini, Amazonas e Dias (2006), embora o casal frequentemente afirme que pensa junto e deseja o filho com a mesma intensidade, é importante considerar que os cônjuges são regidos por uma dinâmica inconsciente. Cada membro do casal tem sua história particular, seus desejos e fantasias em relação ao filho que é esperado. Carlos afirma ter achado um pouco estranho, no início, a presença de uma criança desconhecida em sua casa, mas que, com o passar do tempo, acostumou-se. A decisão inicial de ajudar fora tomada unicamente por Arlete. Dessa maneira, no caso em questão, nota-se uma clara diferenciação entre as motivações, ao menos iniciais, de Carlos e Arlete. A participante, nesse contexto, aparece como uma pessoa de personalidade extremamente forte e resoluta, com enorme influência sobre as decisões que afetam a vida familiar. Tanto que tomou a decisão de acolher Gabriel em sua casa sem ao menos consultar o marido ou os filhos. Arlete afirma que já levara uma mãe e seu bebê para casa em outra ocasião, da mesma forma, sem o consentimento prévio do marido. Tais afirmações parecem condizer com a atitude que Arlete demonstrou durante a realização da entrevista, impondo-se claramente, tomando a iniciativa de responder às questões formuladas e verbalizando mais do que Carlos.

Arlete relata que a reação dos filhos biológicos ante a decisão de adotar caracterizou-se por uma resistência inicial, por parte do filho mais velho. Conta que, no início, Emanoel não se mostrou muito satisfeito com a inclusão de Gabriel na família. Explica que o rapaz, no passado, cuidara de George e Juliano para que ela pudesse trabalhar e, com a chegada do filho adotivo, talvez tenha pensado que seria mais uma responsabilidade que teria de assumir.

Entretanto, com o passar do tempo, a participante afirma que o filho aceitou o irmão mais novo, apegando-se a ele, o que pode ser compreendido como um processo gradual de construção vincular, e não como a ocupação de um lugar previamente reservado para a criança no universo familiar. Emanoel se afeiçou a Gabriel de tal maneira que se mostrou disposto a prover-lhe cuidados nos momentos em que houve necessidade.

No que diz respeito à forma como vivenciaram o exercício da parentalidade adotiva, o casal referiu que Gabriel enfrentou diversas complicações de saúde em seu início de vida.

Ele operou, né, com 10 meses ele teve meningite... Quase morri, quase fiquei doida, porque... Eu só tinha ele e um registro de nascimento dele, mais nada... Ai ele operou, teve meningite, ficou uma semana internado, lá no isolamento. (Arlete)

Para Winnicott (1951/1993), a mãe suficientemente boa é aquela que consegue identificar-se estreitamente com seu filho, adaptando-se ativamente às suas necessidades. Tal adaptação, entretanto, deve diminuir gradativamente ao longo do processo de desenvolvimento, com o fortalecimento da capacidade da criança em tolerar frustrações e assimilar os fracassos da mãe-ambiente. Ao relatar os cuidados que teve em relação à saúde frágil de Gabriel, Arlete parece ter se empenhado para se constituir como uma mãe suficientemente boa, adequando-se às necessidades do filho e provendo-lhe o apoio necessário; a figura materna mostrou-se presente e estável no momento em que o filho necessitava de seus cuidados. Nesse sentido, Arlete parece ter sido capaz de prover holding ao filho, construindo um vínculo descrito por ela em termos positivos. As dificuldades de saúde vivenciadas por Gabriel, nesse sentido, não foram sentidas pela mãe adotiva como um peso, pois parece tê-las enfrentado com disposição e energia. Considerando a importância atribuída por Winnicott (1952/1993) à relação bebê-ambiente, é interessante destacar que o ambiente em questão parece ter se constituído como suficientemente bom para o acolhimento da criança adotiva, favorecendo, assim, seu processo de amadurecimento gradual.

Ademais, os participantes recordam-se de terem enfrentado preconceitos, por parte da família de Arlete, com o processo de adoção. "O quê que foi outro dia que falaram [olha para Carlos]? "Então, se não tivesse pego este menino, não tava passando por isso agora!" Então, esse tipo de coisa que tem que aguentar assim, tem hora." (Arlete). "É... Eu tenho uma tia que adotou... E quando o menino ficou sabendo que era adotivo, virou a casaca." (Carlos)

São vários os preconceitos que circulam no universo da adoção. Dentre eles, pode-se mencionar a crença no "sangue 
ruim": acredita-se que a criança adotiva já traria em seu sangue todas as mazelas, comportamentos e caráter de seus pais biológicos (Andrei, 2001). Na esteira desse suposto "defeito de origem", diversas preconcepções são estabelecidas no sentido de atribuir um lugar desqualificado para o adotado. Segundo Levinzon (2004), é comum encontrar referências à associação entre desenvolvimento psicopatológico e adoção. Não é raro deparar-se com a crença de que a adoção predispõe ao desenvolvimento de problemas psicológicos e comportamentais. A literatura científica, entretanto, não é unânime quanto a esse aspecto (Schettini, Amazonas \& Dias, 2006; Serrano, 2008; Solon, 2009). Segundo Paiva (2004), os problemas geralmente descritos na criança adotiva não podem ser relacionados diretamente e a priori, ao fato de ter sido adotada, nem às vivências traumatizantes anteriores à adoção. Porém, a forma e o momento como se dá a constituição dessa filiação, quem e como são os pais adotivos, a natureza dos vínculos estabelecidos entre pais e filhos e o modo como as vivências da criança são articuladas à sua história de vida são fatores que devem ser considerados quando se busca compreender as vicissitudes da adoção.

Nos trechos destacados, Arlete e Carlos deslocam os preconceitos a respeito da adoção para os familiares. Entretanto, é importante refletir até que ponto tais fantasias, ideias preconcebidas e temores fundamentados em crenças infundadas e preconceituosas, possam também estar presentes no imaginário do casal em questão. Como será exposto a seguir, Arlete parece ter encontrado certa dificuldade para conversar com o filho sobre seu passado. Ademais, os pais fazem referência às dificuldades escolares e comportamentais do filho adotivo, afirmando que ele teria de refazer a primeira série. Explicaram que Gabriel se sai muito bem em disciplinas como música, inglês, informática e educação artística, entretanto, em matemática e português não apresenta um bom desempenho. "Tanto que ele vai refazer a primeira série... Mas a gente, eu já conversei com ele... "Você vai refazer, você já sabe, mas aí você vai fazer pra você aprender mais..." (Arlete)

O casal parece encarar com serenidade as dificuldades de aprendizagem do filho, explicando que ele ainda é muito novo, não vendo, portanto, problema no fato de ele ter de refazer a primeira série escolar. No entanto, o modo como conversam com o filho sobre essa questão parece indicar uma preocupação em preservar sua autoestima, o que também, em geral, constitui um receio relatado por pais em relação a crianças adotadas. Mais uma vez, é importante ressaltar a concepção de Winnicott (1965/997) sobre o sintoma, conceituando-o como um sinal de esperança. As dificuldades escolares levaram os pais de Gabriel a procurarem atendimento psicológico para o filho em uma clínica-escola de Psicologia. Gabriel foi atendido por um período de um ano e quatro meses, bem como sua mãe. É interessante notar, dessa forma, que o sintoma constituiu-se como um fator que deflagrou a busca de auxílio profissional externo, no sentido de procura por recursos no ambiente mais amplo, na própria comunidade, para lidar com os impasses do amadurecimento da criança e de sua relação com a família e o ambiente escolar.

É essencial destacar, a partir do discurso do casal, o medo da perda do filho adotivo, presente na vivência de Arlete, bem como seu sentimento de traição em relação à mãe biológica de Gabriel.

Nossa Senhora... Porque às vezes eu fico pensando... Engraçado, eu precisava tirar isso da cabeça... Porque eu falei pra ela [mãe biológica de Gabriel] que eu cuidava, e depois, o quê que eu fiz? Acabei foi ficando com o menino dela, né? Então, parece que dá aquela sensação, assim, de traição, né? (Arlete)

A literatura refere que são comuns as fantasias de "roubo" por parte dos pais adotivos que, ao "retirarem o filho" de sua mãe biológica, sentem como se a tivessem privado da maternidade (Gomes \& Iyama, 2001; Levinzon, 2004). A adoção, nesse contexto, é tratada como um ato delitivo, o que acaba por gerar intensos sentimentos de culpa e, em consequência, medo de represálias. A fantasia de traição tornaria explícito o medo de ser punida com a perda da criança (Vargas, 1998). Na fala de Arlete fica evidente o desconforto que ela experimenta por ter se apropriado do filho de outra mulher: a participante relata sentir a adoção como uma traição à mãe biológica de Gabriel, temendo, ainda, que a mesma possa retornar a qualquer momento e tomar-lhe o filho "roubado". Poderia ocorrer, ainda, de o filho desejar o rompimento dos laços afetivos. Esse receio é reforçado pelo fato de Joana, a mãe biológica, residir nas proximidades da casa da família. A traição, nesse sentido, seria reeditada: o filho trairia os pais adotivos, os quais sentem que traíram a mãe biológica.

E é engraçado que, mesmo ele estando registrado no nosso nome e tudo, parece que... O medo, a sensação de perda está sempre ainda por cima [baixa o tom de voz]... Esses tempos, acho que foi ano passado, né? Você lembra quando eu falei que encontrei a Joana no supermercado? Menina, estava eu e o Gabriel no supermercado... Se eu achasse um buraco na prateleira, eu socava ele dentro. (Arlete)

Por este relato, a assim chamada adoção pronta, mesmo sendo oficializada/legalizada depois de a criança estar convivendo há pelo menos dois anos com a família adotante com o devido consentimento da genitora (no caso, a mãe biológica encontrava-se ciente de que a criança estava sendo cuidada pelo casal em questão, embora tenha combinado, inicialmente, que iria buscá-lo posteriormente), acaba contribuindo para estimular a fantasia de Arlete de roubo/perda do filho. Sendo assim, não se tratam apenas de fantasias inconscientes, mas também daquilo que se apóia em dados de realidade, pela contravenção operada pelo casal ao assumir mais do que os cuidados prometidos que asseguraram a subsistência de Gabriel, mas também o vínculo de parentalidade, que culminou com a destituição da filiação biológica. Mesmo com a legalização da adoção, o espectro da apropriação indevida da criança de outrem parece continuar latente no imaginário da mãe adotiva, a qual revela temer que, um dia, Joana retorne para recuperar Gabriel. Parece acreditar, assim, que a mãe biológica regressaria, mais cedo ou mais tarde, para cumprir o acordo informal que celebraram originariamente, reivindicando a posse do menino que, no imaginário de Arlete, ainda pertenceria à mãe biológica.

No caso em questão, embora não se possa postular a inveja em relação à fertilidade dos pais biológicos, posto que 
Carlos e Arlete foram capazes de exercer a parentalidade pelas vias biológicas, pode-se refletir a respeito de uma falta de segurança em relação à estabilidade do vínculo existente entre pais e filho adotivo (Levinzon, 2006) e também acerca dos aspectos legais desse processo. A fantasia de roubo acaba tendo respaldo em um dado de realidade, na medida em que, se considera o pacto explícito da adotante com a genitora que corresponderia a fazer uma Guarda e não Adoção, tendo em vista que a adotante prometera à mãe biológica que ela poderia voltar a qualquer momento e reaver a criança.

A legítima parentalidade parece estar relacionada, nesse sentido, tanto aos laços consanguíneos (em detrimento dos laços socioafetivos, construídos por meio da adoção), quanto ao modo como foi realizada a adoção. Assim, podemos depreender que a participante relata não apenas a necessidade de contar com maior segurança afetiva, como também de segurança jurídica (Ghesti-Galvão, 2008): o medo e a insegurança aparecem no discurso da mãe adotiva estreitamente relacionados ao contrato que ela estabelecera com a genitora de Gabriel. No início, Arlete prometera que cuidaria do menino, mas não que o faria deixar de ser filho de Joana. Ou seja, Arlete entende que poderia ter mantido a promessa (cuidar) sem romper o vínculo de filiação anterior, o que explica o sentimento de ter "traído" a confiança de Joana.

$\mathrm{Na}$ legislação sobre a adoção (ECA, 1990; Brasil, 2009), existe a previsão do consentimento explícito dos pais biológicos para adoção, o que não ocorreu nesse caso. A ausência de concordância explícita nos permite pensar que Arlete sofre intensamente com um sentimento de culpa que tem sustentação na realidade, situação que perdura mesmo depois da legalização da adoção. O exercício da parentalidade adotiva se dá em meio a temores e fantasias de perda, ainda mais quando abordamos o contexto das chamadas adoções prontas ou diretas. Estudo de Mariano e Rossetti-Ferreira (2008), que acompanhou 110 processos de adoção ocorridos no período de 1991 a 2000 na Comarca de Ribeirão Preto, SP, comprovou que $70 \%$ correspondiam a adoções diretas. Após a vigência da nova lei da adoção (Brasil, 2009), resta questionar em futuros estudos se tal fantasia/realidade de roubo/perda se manteria nas adoções realizadas nos moldes legais, mediante inscrição prévia, tanto de adotantes como de crianças potencialmente passíveis de adoção, junto às Varas da Infância e da Juventude. No caso das crianças/ adolescentes, prevê-se a realização de estudo psicossocial prévio de sua condição de adotabilidade, em que se inclui a atenção psicossocial à família de origem (no mínimo, à mãe biológica). Além disso, a adoção legal envolve agora a preparação para a parentalidade adotiva.

Em relação à revelação ao filho sobre a adoção, Carlos e Arlete afirmam que Gabriel já sabe que, biologicamente, é filho de outras pessoas. O casal fez várias tentativas de explicar ao filho essa realidade, ao que ele parecia não compreender muito bem, até que, há algum tempo, Arlete contou-lhe sobre a adoção de uma forma mais direta. Relata que Gabriel mostrou-se agitado quando soube da verdade e que levou muito tempo para tocar no assunto novamente. Segundo Maldonado (1989), as perguntas e conversas sobre a adoção, por se tratarem de temas ansiogênicos, costumam surgir intercaladas por extensos períodos de tempo, nos quais parece não haver mais interesse no assunto. Atualmente, o filho tem preferido não falar sobre sua história pregressa, optando, assim, por manter silêncio sobre seu passado.

Porque sempre a gente vinha falando, sempre vinha falando, que ele não é da barriga, que ele é do coração... O George é da barriga, o Emanoel é da barriga, o Juliano é da barriga, ele não, ele é do coração... E eu, como eu tenho essa cicatriz aqui [aponta para marca próxima ao pescoço], eu acho que ele, que ele falava: "eu sai daqui, então?" Ai eu falei: "não, você saiu da barriga de outra mulher." Ai ele perguntou quem que era a mulher... Ai eu falei: "Ó, ela foi embora, ela não apareceu mais". Mas nunca contei a história, sabe, que ela abandonou, que ele passava fome com ela... Eu não quero... Eu quero poupar ele disso... Então é assim, ele pergunta... Falei: "A gente ama muito você, a gente amava muito você, por isso você ficou com a gente... E ela foi embora, ai você ficou com a gente, porque a gente ama muito você..." (Arlete)

Ainda que não existam elementos suficientes, a partir do que se pôde apurar durante a entrevista é possível questionar se a mãe biológica realmente abandonou ou entregou esse filho aos cuidados de Arlete. Motta (2001), ao contrário do que permeia o imaginário social, afirma que a decisão de entregar um filho em adoção pode ter vários significados, desde assumir a impossibilidade de criá-lo, admitir sua rejeição à criança ou aceitar a frustração do amor e do desejo de maternagem. Pela nova lei da adoção (Brasil, 2009), a mãe que quiser entregar seu filho (nascituro) à adoção terá assegurada assistência psicológica e jurídica do Estado, devendo ser encaminhada à Vara da Infância e Juventude.

Winnicott (1955/1997) postula que a revelação sobre as origens da criança deve ser realizada precocemente, posto que o mistério a respeito do passado gera uma mistura entre fato e fantasia. Assim, amor, desgosto e horror são sentimentos iminentes na criança, devendo ser experimentados para serem elaborados e deixados para trás, no seu devido tempo. Pode-se refletir, assim, que a dificuldade de diálogo a respeito do passado do filho possa estar relacionada às fantasias de "roubo" presentes nos pais em questão. Parece persistir o medo de que Gabriel possa voltar aos seus pais biológicos, caso conheça e tenha contato com os mesmos; um temor de que venham reivindicar sua criança "roubada" e que esta opte pela família de origem em detrimento da adotiva. Haveria, nesse sentido, um temor latente de que Gabriel "vire a casaca", caso venha a conhecer seus pais biológicos. Frente a essas considerações, pode-se imaginar por que razões o casal evita tanto falar sobre o assunto e, consequentemente, posterga a abertura de um diálogo franco e aberto sobre a verdadeira origem da criança, o que inibe ou impede que o filho mantenha ativa sua curiosidade e faça perguntas a respeito de seu passado. Nessa vertente, o silêncio da criança, mesmo após ter sido inteirada da verdade pelos pais adotivos - ainda que uma verdade parcial, já que a identidade da mãe biológica continua a ser escamoteada - é sinal de interrupção dos processos investigativos que ela começou a desenvolver, ao explorar suas origens. Essa suspensão da curiosidade pode contribuir para sua inibição intelectual, que está na raiz dos problemas de aprendizagem evidenciados na escola. 
No que diz respeito ao relacionamento entre pais e filhos, é importante salientar que as semelhanças e diferenças entre os filhos biológicos e adotivo são bastante enfatizadas no discurso de Carlos e Arlete. O casal faz questão de salientar que os filhos são criados em condição de igualdade.

Bom, eu pelo menos tento fazer tudo igual... O Carlos também, nunca foi de... O Gabriel é sempre o mais mimado porque ele é o mais novinho, né? Aliás, todo o mundo mima ele, né, até o gato e o cachorro. (Arlete)

Carlos e Arlete justificam a superproteção e os cuidados especiais dispensados a Gabriel devido à diferença de idade entre os filhos. Assim, por ser o mais novo, ele seria o mais mimado, fato que não estaria relacionado, segundo os pais, à sua história de adoção. Nesse sentido, as diferenças percebidas entre os filhos estariam associadas à faixa etária e não à condição de biológico ou adotivo. É possível relacionar tal achado a uma tentativa compensatória de combater preconceitos presentes no contexto da adoção. O casal, dessa maneira, perceberia e trataria os filhos da mesma forma, para que eles se sentissem igualmente amados e protegidos, o que garantiria que a condição de afiliação biológica em nada influenciasse os relacionamentos intrafamiliares.

A negação de que a parentalidade e a filiação adotivas sejam diferentes é bastante comum em nossa sociedade. A dificuldade de lidar com o diferente, nesse contexto, conduziria a uma tentativa de trazê-lo para o espaço da "normalidade". Schettini, Amazonas e Dias (2006) postulam que, para a sociedade em geral, existe uma única possibilidade de construir a diferença: por meio do pleno reconhecimento da exclusão. Entendemos que a questão é assumir a diferença não para legitimá-la ou justificá-la, mas como uma condição que dignifica a singularidade. Portanto, reconhecer a condição peculiar de cada filho, independentemente de suas origens, configura-se ainda como um desafio para o casal investigado.

De modo geral, o relacionamento entre pais e filhos é conotado positivamente pelo casal, sendo caracterizado pela proximidade. O casal relata que existe sentimento de união entre os membros da família, disponibilidade e espaço para promover o diálogo e preocupação, por parte de pais e filhos, com o bem comum. O ambiente familiar, nesse sentido, parece ser capaz de atender às necessidades dos filhos, proporcionando-lhes um contexto favorável de desenvolvimento.

No que concerne ao relacionamento entre irmãos, o casal recorre novamente ao discurso da normalidade, com o qual tenta minimizar e homogeneizar as diferenças entre os filhos. Nota-se uma tentativa de naturalizar o relacionamento fraterno, tornando-o próximo àquele vivenciado em famílias compostas somente por irmãos biológicos. Para Costa e Rossetti-Ferreira (2007), algumas pessoas que buscam a adoção estão tomadas por concepções de maternidade, paternidade e família que valorizam o modelo biológico de parentalidade, o que poderia explicar o desejo do casal de "normalizar" o relacionamento fraterno dos filhos. Mais uma vez, pode-se pensar que a diferença é sentida na família como algo não desejável, excludente, que por isso deve ser negado e evitado.

Carlos e Arlete relatam, ainda, que os filhos conversam muito entre si, apesar das brigas corriqueiras. Referem-se ao ciúme que parece existir entre os rapazes, com eventuais discussões sobre qual filho seria o preferido da família. Novamente, parece haver uma tentativa de negar possíveis diferenças no relacionamento parental. É importante pensar que, embora os filhos de Arlete e Carlos possivelmente sintam que os pais os tratam de maneiras distintas, o casal tenta invalidar tal percepção. O casal explica que se trata de uma tentativa de não "fazer diferença" entre seus filhos, pois acreditam que, tratando-os de forma igualitária, eles se sentiriam igualmente amados.

Arlete faz referência aos cuidados dos filhos biológicos em relação ao filho adotivo. Segundo estudo realizado por Fernandes, Alarcão e Raposo (2007), percebeu-se que os irmãos mais velhos são mais conscienciosos (mais obedientes ao dever e mais deliberados), menos hostis e mais altruístas do que os do meio. Os mais velhos, desse modo, são vistos como aqueles que mais seguem os padrões de conduta, princípios éticos e obrigações morais, recebendo a responsabilidade de serem os guardiões detentores das normas e valores familiares. Tal achado encontrado na literatura científica parece condizente com a descrição que Arlete faz de Emanoel: considera-o o mais responsável dos filhos, aquele que mais auxiliou no cuidado dos irmãos, por ser o primogênito. Dessa forma, parece assumir um papel de cuidador na família em questão, educando e contribuindo com a formação dos irmãos mais novos.

Pode-se inferir, a partir dessa análise, que a adoção não é um processo que se limita aos cuidados supridos pelas figuras parentais, mas envolve e mobiliza o restante da família, em particular os filhos mais velhos. Como destacado pela teoria winnicottiana, o ambiente suficientemente bom, inicialmente constituído pela mãe, amplia-se a partir da inclusão do pai, da família como um todo, no caso, os irmãos, e de toda a sociedade (Frota, 2006). No caso em questão, houve convergência na questão dos filhos mais velhos também "adotarem" o irmão adotivo, o que se traduz, no cotidiano, no provimento de afeto, proteção, segurança e cumplicidade. Esses cuidados ajudam a consolidar o ambiente suficientemente bom e confiável de que a criança necessita para sustentar seu amadurecimento (Winnicott, 1965/1997). Considerando a peculiaridade da criança adotada, essa adaptação ativa dos pais, que é reforçada e ampliada pelo apoio e supervisão permanente dos irmãos mais velhos, ajuda a solidificar o sentimento de inclusão e pertença ao núcleo familiar, contribuindo para atenuar o processo traumático de rompimento precoce dos vínculos familiares que está na origem de qualquer adoção.

Ademais, é possível apreender, a partir do discurso do casal em questão, a proximidade afetiva entre os irmãos. Carlos e Arlete relatam que os filhos costumam ajudar uns aos outros e preocupam-se com o bem-estar dos demais familiares. Mais uma vez, destaca-se o papel ocupado por Emanoel, o filho mais velho, na família em questão. O primogênito parece figurar como um segundo pai para os irmãos mais novos, biológicos e adotivo; preocupa-se com a formação profissional dos mesmos e contribui financeiramente para sua educação.

Os planos que o casal tece para o futuro estão vinculados ao êxito profissional dos filhos; esperam que os mesmos arranjem bons empregos (melhores que os atuais) e que Gabriel possa estudar em uma boa escola. Nota-se, assim, 
uma preocupação a respeito do futuro dos filhos, os quais, segundo Carter e McGoldrick (1995), seriam o elemento que garantiria a continuidade do sistema familiar, a permanência dos legados transmitidos às próximas gerações e a herança consumada por meio da realização dos descendentes. Os filhos, nesse sentido, seriam o depositário dos melhores sonhos e esperanças dos pais, e também a forma que estes encontraram de se perpetuarem e continuarem a existir no mundo, transcendendo sua finitude.

\section{Considerações finais}

O processo de adoção discutido neste estudo mostrou-se envolvido em intensa carga emocional, permeado por afetos ambivalentes. A partir dos dados obtidos, pode-se concluir que a origem da adoção, o modo como a criança foi inserida no novo núcleo familiar, as motivações e a maneira como o processo de adoção se configura na realidade do lar substituto podem impactar o desenvolvimento posterior da criança e seu relacionamento intrafamiliar. Sendo assim, é preciso favorecer tanto condições para que os pais possam refletir a respeito de seus temores e fantasias, de modo a se fortalecerem e encontrarem segurança no exercício de seu papel como cuidadores legítimos, quanto informá-los e fornecer suporte acerca dos aspectos legais que envolvem a adoção.

Nesse sentido, no caso relatado constatou-se a relutância dos pais em revelar ao filho adotivo sua história inicial de vida, o que se ancora tanto em fantasias inconscientes de roubo/perda quanto em um discurso consciente, derivado de um dado real de contravenção do pacto estabelecido com a mãe biológica da criança. Essas fantasias ainda não puderam ser elaboradas e ressignificadas. Nesse contexto, abrir canais para uma comunicação aberta, bem antes da consumação da adoção em si, pode contribuir para a construção de um vínculo parental baseado na confiança, facilitando o desenvolvimento saudável da criança. Nessa direção, o projeto de adoção não apenas deve ser desenvolvido, elaborado e amadurecido pelo casal adotante, mas também pelo seu entorno familiar - o que, no caso em apreço, inclui os filhos biológicos - e pela família de origem da criança (pelo menos na figura de sua genitora). Não é apenas a parentalidade adotiva que está em jogo, mas toda uma reorganização familiar que se dá em função da adoção.

A adoção suficientemente boa, como propõe o fio condutor deste estudo, não pode ser entendida apenas como um evento bem-sucedido de integração da criança em um lar substituto. Trata-se de um longo processo no qual os familiares, os pais e a própria criança se esclarecem, identificam-se e se enriquecem mutuamente - e, portanto, se transformam, na medida em que assumem/negociam posições que contribuem para a construção de um ambiente saudável, no qual papéis, escolhas, finalidades, valores e necessidades sejam congruentes. A família que consegue levar a cabo a adoção não como um processo normalizante, mas criativo e transformador, pode promover a instauração de um projeto que realmente contribua para o desenvolvimento de todos os seus membros, sendo receptáculo contenedor de angústias ou fantasias destrutivas que podem coexistir e serem elaboradas, dando espaço às possibilidades de encontro, aprendizado compartilhado e construção de laços afetivos sólidos e duradouros.

Compreender, a partir de um estudo de caso, o modo como se configurou a adoção em um contexto localizado, mostrou-se essencial para que novos olhares e práticas sociais, fundamentadas do ponto de vista psicológico, social e jurídico, possam ser empregadas, conduzindo a desfechos bem-sucedidos. Assim, é preciso que os profissionais estejam não apenas conscientes do papel que desempenham nesse contexto, mas que conheçam a legislação vigente e as formas de oferecer apoio à tríade formada por adotantes, adotado e família de origem do adotado (Ghesti-Galvão, 2008).

O presente estudo contribui com novas reflexões que permitem avançar na compreensão das peculiaridades da dinâmica de famílias que, mesmo após terem seus filhos biológicos, optam pela adoção. Obviamente, a abordagem desses casos não pode considerar mais a impossibilidade de gestação biológica como deflagrador da busca da parentalidade por via adotiva, mas desvelar outras motivações, desejos, intencionalidades e devires subjacentes ao processo de adoção.

\section{Referências}

Andrei, E. (2001). Adoção: mitos e preconceitos. In F. Freire (Ed.), Abandono e adoção: Contribuições para uma cultura da adoção III (pp. 41-50). Curitiba: Terra dos Homens.

Brasil (2009). Lei n. 12.010, de 3 de agosto de 2009 (2009). Dispõe sobre adoção; altera as Leis n. 8.069, de 13 de julho de 1990 - Estatuto da Criança e do Adolescente, 8.560, de 29 de dezembro de 1992; revoga dispositivos da Lei n ${ }^{\circ} 10.406$, de 10 de janeiro de 2002 - Código Civil, e da Consolidação das Leis do Trabalho - CLT, aprovada pelo Decreto-Lei ${ }^{\circ} 5.452$, de $1^{\circ}$ de maio de 1943; e dá outras providências. Brasília, DF.

Carter, B., \& McGoldrick, M. (1995). As mudanças no ciclo de vida familiar: Uma estrutura para a terapia familiar (M. A. V. Veronese, Trad.). Porto Alegre: Artes Médicas.

Costa, N. R. A. (2005). Construção de sentidos relacionados à maternidade e à paternidade em uma família adotiva. Tese de Doutorado, Universidade de São Paulo, São Paulo.

Costa, L. F., \& Campos, N. M. V. (2003). A avaliação psicossocial no contexto da adoção: vivências das famílias adotantes. Psicologia: Teoria e Pesquisa, 19, 221-230.

Costa, N. R. A., \& Rossetti-Ferreira, M. C. (2007). Tornar-se pai e mãe em um processo de adoção tardia. Psicologia: Reflexão e Crítica, 20, 425-434.

Fernandes, O. M., Alarcão, M., \& Raposo, J. V. (2007). Posição na fratria e personalidade. Estudos de Psicologia, 24(3), 297-304.

Frota, A. M. (2006). A reinstalação do si-mesmo: uma compreensão fenomenológica da adolescência à luz da teoria do amadurecimento de Winnicott. Arquivos Brasileiros de Psicologia, 58(2), 51-66.

Ghesti-Galvão, I. (2008). Intervenções psicossociais e jurídicas no percurso da adoção: A mediação entre o afeto e a lei. Tese de Doutorado, Universidade de Brasília, Brasília.

Gomes, I. C., \& Iyama, R. (2001). Atendimento breve de orientação psicanalítica a pais de crianças adotivas. Boletim de Psicologia, 114(51), 109-121.

Gomes, K. P. S. (2006). A adoção à luz da teoria winnicottiana. Winnicott e-prints, 1, 1-33. 
Iyama, R., \& Gomes, I. C. (2005). A adoção sob um "olhar" winnicottiano. Encontro: Revista de Psicologia, 10(12), 58-70.

Levinzon, G. K. (2004). Adoção. São Paulo: Casa do Psicólogo.

Levinzon, G. K. (2006). A adoção na clínica psicanalítica: o trabalho com os pais adotivos. Mudanças: Psicologia da Saúde, 14(1), 24-31.

Mariano, F. N., \& Rossetti-Ferreira, M. C. (2008). Que perfil da família biológica e adotante, e da criança adotada revelam os processos judiciais? Psicologia: Reflexão e Crítica, 21, 11-19.

Maldonado, M. T. (1989). Maternidade e paternidade. Petrópolis, RJ: Vozes.

Motta, M. A. P. (2001). Mães abandonadas: A entrega de um filho em adoção. São Paulo: Cortez.

Otuka, L. K. (2009). Adoção por famílias com filhos biológicos: A perspectiva dos casais adotantes. Monografia não-publicada, Faculdade de Filosofia, Ciências e Letras de Ribeirão Preto, Universidade de São Paulo.

Paiva, L. D. (2004). Adoção: Significados e possibilidades. São Paulo: Casa do Psicólogo.

Palacios, J., Sánchez-Sandoval, Y., \& León, E. (2004). Adelante con la adopción. Sevilla, Junta de Andalucia: Consejeria para la Igualdad y Bienestar Social.

Pereira, J. M. F., \& Santos, M. A. (1998). O enfoque psicológico da adoção: revisão da literatura. In R. C. Labate (Ed.), Caminhando para a assistência integral (pp. 225-247). Ribeirão Preto, SP: Scala.

Peres, R. S., \& Santos, M. A. (2005). Considerações gerais e orientações práticas acerca do emprego de estudos de caso na pesquisa científica em Psicologia. Interações, 20(10), 109-126.

Rosa, D. B. (2008). A narratividade da experiência adotiva: fantasias que envolvem a adoção. Psicologia Clínica, 20(1), 97-110.

Santos, M. A., Raspantini, R. L., Silva, L. A. M., \& Escrivão, M. V. (2003). Dos laços de sangue aos laços de ternura: o processo de construção da parentalidade nos pais adotivos. Psic, 4(1), 14-21.

Sarti, C. A. (1996). A família como espelho. Campinas, SP: Autores Associados.

Schettini, S. S. M., Amazonas, M. C. L. A., \& Dias, C. M. S. B. (2006). Famílias adotivas: identidade e diferença. Psicologia em Estudo, 11(2), 285-293.

Scorsolini-Comin, F., \& Santos, M. A. (2008). Aprender a viver é o viver mesmo: o aprendizado a partir do outro em um grupo de pais candidatos à adoção. Vínculo, 5(2), 115-130.
Serrano, S. A. (2008). O abrigamento de crianças de zero a seis anos em Ribeirão Preto: Caracterizando esse contexto. Tese de Doutorado, Universidade de São Paulo, São Paulo.

Solon, L. A. G. (2009). Conversando com crianças sobre adoção. São Paulo: Casa do Psicólogo.

Triviños, A. N. S. (1987). Introdução à pesquisa em ciências sociais: a pesquisa qualitativa em educação. São Paulo: Atlas.

Vargas, M. M. (1998). Adoção tardia: Da família sonhada à família possivel. São Paulo: Casa do Psicólogo.

Winnicott, D. W. (1982). A criança e seu mundo (A. Cabral, Trad.). Rio de Janeiro: Guanabara Koogan (Original publicado em 1957).

Winnicott, D. W. (1990). Provisão para a criança na saúde e na crise. In $O$ ambiente e os processos de maturação: Estudos sobre a teoria do desenvolvimento emocional (I. C. S. Ortiz, Trad., pp. 62-69). Porto Alegre: Artes Médicas (Original publicado em 1962).

Winnicott, D. W. (1993). Objetos transicionais e fenômenos transicionais. In Textos selecionados: Da pediatria à psicanálise. (J. Russo, Trad., pp. 389-408). Rio de Janeiro: Francisco Alves (Original publicado em 1951).

Winnicott, D. W. (1993). Psicose e cuidados maternos. In Textos selecionados: Da pediatria à psicanálise (J. Russo, Trad., pp. 491-498). Rio de Janeiro: Francisco Alves (Original publicado em 1952).

Winnicott, D. W. (1997). A adolescência das crianças adotadas. In Pensando sobre crianças (M. A. V. Veronese, Trad., pp. 131-140). São Paulo: Artmed (Original publicado em 1955).

Winnicott, D. W. (1997). Armadilhas na adoção. In Pensando sobre crianças (M. A. V. Veronese, Trad., pp. 126-130). São Paulo: Artmed (Original publicado em 1954).

Winnicott, D. W. (1997). Duas crianças adotadas. In Pensando sobre crianças (M. A. V. Veronese, Trad., pp. 115-125). São Paulo: Artmed (Original publicado em 1953).

Winnicott, D. W. (1997). A família e o desenvolvimento individual. (M. B. Cipolla, Trad.). São Paulo: Martins Fontes (Original publicado em 1965).

Recebido em 11.12.2009

Primeira decisão editorial em 21.09.2010

Versão final em 04.10.2010

Aceito em 02.12.2010 